Practical School Gardening. By P. Elford and S. Heaton. Second Edition. Pp. 224. (Oxford: At the Clarendon Press, I921.) $3 s .6 d$. net.

Messrs. Elford and Heaton have had very considerable experience in organising school gardens and making them fit into the educational scheme, and they have produced a volume which has already proved its usefulness, so that it now passes into a second edition. The authors insist that the combination of School Gardening and Nature Study when properly co-ordinated with the rest of the work in the school can be, and often are, a valuable means of education. Most teachers would agree, but difficulties do undoubtedly arise when an attempt is made to put this excellent general principle into practice. Given a plot of ground, a class, and a limited but definite time each week, how is the teacher to proceed in order that the children may derive the maximum educational benefit? The practical details that need attention, the pests, weeds, and other troubles that are likely to cause trouble, and the many difficulties that crop up as soon as one begins to cultivate the soil, are effectively dealt with. The authors urge that a school reference library might with advantage be formed, but they give no suggestions to this end. In a future edition a list of suitable books might well be added.

\section{Laboratory Manual of the Technic of Basal Metabolic} Rate Determinations. By Dr. W. M. Boothby and Dr. Irene Sandiford. Pp. II7. (Philadelphia and London: W. B. Saunders Company, r920.) Price 24s. net.

THE authors consider that the results of indirect calorimetry should not be thrown into general discredit as a means of clinical diagnosis, by neglect of details requisite for a true basal metabolic rate. In their well-illustrated book they have certainly set a good example in the matter of detail. They describe the method in use at the Mayo Clinic, Rochester, Minnesota. The patient inspires the atmospheric air through a mask, and the expired air is collected and measured in a gasometer (Tissot) from which samples of air are taken for analysis of carbon dioxide and oxygen by the Haldane gas analysis apparatus, the calculations being carried out as usual. The advantages of this method, and perhaps the disadvantages of other methods, are somewhat emphasised. The authors deserve credit for the very careful directions for all stages of the technique. The book contains a special note for calculation of metabolic rate of a diabetic, a bibliography, an appendix with all the tables required for calculations, and an index. Indirect calorimetry has certainly proved its value in cases of thyroid disease.

Some Account of the Oxford University Press, I468I921. Pp. I12. (Oxford: Clarendon Press, r922.) $5 s$.

THIS is a charming monograph describing the work of a great institution. The book is a masterpiece of typography, and is embellished by a number of reproductions of old woodcuts and recent photographs. Special chapters are devoted to its most important publications - the Oxford English Dictionary and the Dictionary of National Biography. The vast opera- tions of the Press may be judged by the fact that its warehouses at Oxford are estimated to contain $3 \frac{1}{2}$ million copies of about 4500 distinct works. From these vaults was drawn into the upper air, in 1907 , the last copy of Wilkins's "Coptic New Testament," published in $17 \times 6$, the paper scarcely discoloured and the impression still black and brilliant. During the War, the Press carried out much confidential work for the Naval Intelligence Department, and supplied during three years $4 \frac{1}{2}$ million copies of the New Testament for use in the field. The relations of the Press to its servants have always been amicable, and the case of the late Mr. J. C. Pembrey, one of the proofreaders, is probably unique: in 1847 he read Wilson's "Sanskrit Grammar," and in I916 the "Vedic Grammar" of Prof. Macdonell.

\section{Animal Life of the British Isles: A Pocket Guide to the} Mammals, Reptiles, and Batrachians of Wayside and Woodland. By E. Step. (The Wayside and Woodland Series.) Pp. vii + I84 + III plates. (London and New York: Frederick Warne and Co., Ltd., I92I.) Ios. $6 d$. net.

ThIs handy little volume will be welcomed by a large number of amateur naturalists, and can be cordially recommended to all who wish for full and accurate knowledge of the habits, life histories, and appearances of those members of the British fauna that are included in the three classes specified in the sub-title. Hitherto it has not been possible to secure such information within the covers of a single small volume, nor in any one work at so low a price. The illustrations are excellent, the plain being from the work of our best naturalist photographers, such as Messrs. Douglas English, Oxley Grabham, and others, while forty-eight photographs in the natural colours are to the credit of $\mathrm{Mr}$. W. J. Stokoe. The co-operation of these talented artists with the author results in a very satisfactory pocket guide.

\section{British Insect Life: A Popular Introduction to Ento.} mology. By E. Step. Pp. $264+32$ plates. (London: 'T. Werner Laurie, Ltd., N.D.) ros. 6 d. net.

AтteMPts to give "popular" accounts of the several orders, families, and other subdivisions into which insects are classified almost invariably fail from lack of the courage needed to set before the general reader those details of structure that must be mastered in order to discriminate order from order, genus from genus, and, still more, species from species. In the absence of such information books such as this by Mr. Step become, except to those already versed in entomology, meaningless in many of their pages. We should welcome statements which would enable the enthusiastic beginner to determine whether the specimen in his hand was, say, a stone-fly, a may-fly, a lacewing-fly, or a caddis-fly; and others rendering clear the structural differences between, say, the pierid and the nymphalid butterflies; and so on. We decline to believe that shirking the difficulties will ever popularise or in any way benefit the science of entomology. The figures in the plates of this book are unfortunately not numbered; thus the uninstructed reader is left in doubts as to the application of the numbers given in the respective legends.

$$
\text { NO. } 2738 \text {, VOL. IOg] }
$$

